\title{
Erratum to: Posttreatment PET-CT-Confirmed Intrahepatic Radioembolization Performed Without Coil Embolization, by Using the Antireflux Surefire Infusion System
}

\author{
Andor F. van den Hoven • Jip F. Prince - Morsal Samim • \\ Aravind Arepally • Bernard A. Zonnenberg • Marnix G. E. H. Lam • \\ Maurice A. A. J. van den Bosch
}

Published online: 17 August 2013

(C) Springer Science+Business Media New York and the Cardiovascular and Interventional Radiological Society of Europe (CIRSE) 2013

\section{Erratum to: Cardiovasc Intervent Radiol}

\section{DOI 10.1007/s00270-013-0674-3}

The family name of the fifth author was published with a misspelling. The correct spelling (Zonnenberg) appears in this erratum.

The online version of the original article can be found under doi:10.1007/s00270-013-0674-3.

\footnotetext{
A. F. van den Hoven $(\bowtie)$. J. F. Prince - M. Samim .

B. A. Zonnenberg · M. G. E. H. Lam .

M. A. A. J. van den Bosch

Department of Radiology and Nuclear Medicine, University

Medical Center Utrecht, Heidelberglaan 100, 3584 CX Utrecht,

The Netherlands

e-mail: a.f.vandenhoven@umcutrecht.nl

J. F. Prince

e-mail: j.prince@umcutrecht.nl

M. Samim

e-mail: m.samim-3@umcutrecht.nl

B. A. Zonnenberg

e-mail: b.zonnenberg@umcutrecht.nl

M. G. E. H. Lam

e-mail: m.lam@umcutrecht.nl

M. A. A. J. van den Bosch

e-mail: mbosch@umcutrecht.nl

A. Arepally

Department of Interventional Radiology, Piedmont Healthcare,

Atlanta, GA 30309, USA

e-mail: aarepal@gmail.com
} 